Revista Complutense de Educación

ISSNe: 1988-2793

http://dx.doi.org/10.5209/RCED.63985

\title{
Pedagogías sensibles. Sabores y saberes del cuerpo y la educación
}

Autor: Jordi Planella Ribera

Editorial: Edicions de la Universitat de Barcelona

Año de publicación: 2017

$N^{o}$ de páginas: 132

ISBN: 978-84-475-4118-8

Hace ya algunos años que algunas editoriales universitarias están impulsando colecciones de libros sobre educación. En los catálogos de esas colecciones hallamos, sin duda, manuales académicos dirigidos a estudiantes y profesores universitarios, pero hay quien está haciendo apuestas decididas por publicar trabajos menos corrientes y experimentales sin perder el rigor académico ni el deseo de intervenir en el debate educativo actual. Es el caso de la colección "Pedagogías UB” del sello editorial de la Universidad de Barcelona, dirigida por el profesor Enric Prats. En los dos últimos años, el profesor Enric Prats ha insuflado un nuevo aliento a la colección, tal y como lo demuestra la publicación de Pedagogías sensibles. Sabores y saberes del cuerpo y la educación, de Jordi Planella.

Jordi Planella es catedrático de Pedagogía Social en la UOC. A pesar de lo que pueda indicar su categoría docente, no es alguien que haya seguido una trayectoria académica clásica, puesto que cuenta con una larga experiencia laboral como educador social en el sistema de protección a la infancia y la adolescencia y, sobre todo, en el campo de la diversidad funcional. Tal vez por ello, su producción académica es difícil de encorsetar. En este libro, uno puede intuir cómo trabaja, o lo que es lo mismo, cómo lee y cómo estudia, dos actividades cada vez más insólitas de ver y practicar en la universidad. En efecto, Pedagogías sensibles es el resultado de su propia práctica de pensamiento, que bien puede describirse como la práctica del collage. Lejos de tratarse de una vacuidad postmoderna, Jordi Planella nos presenta un libro que es, a su vez, cuaderno de bitácora y diario de navegación, es decir, un "libro-herramienta". Decimos esto porque en él hallamos tres niveles de escritura diferentes. Por un lado, la escritura propia del ensayo académico, en la que el autor juega con las citas de autoría para desarrollar sus ideas a modo impresionista, acomodándose al ritmo de unas lecturas que anota al ritmo de su escritura para que el lector encuentre hilos que poder estirar. Por el otro, aparecen las "cajas de herramientas y de pensamientos", que en el texto se nos muestran enmarcadas en pequeños recuadros bajo títulos diferentes. En primer lugar, las “box”, que le sirven para hacer pequeñas digresiones al hilo de sus argumentos y, en segundo lugar, los recuadros que él denomina bajo el epígrafe "segunda piel", donde recoge pensamientos fugaces de carácter más personal escritos a vuela pluma.

Pedagogías sensibles da continuidad al trabajo que Planella inició en su tesis doctoral, publicada en Descleé De Brouwer el año 2006 con el título Cuerpo, cul- 
tura y educación. Esta vez, sin embargo, ha escrito un libro que intenta partir de la experiencia de aquello que encarna. Así, no le interesa tanto hacer una reflexión sobre el cuerpo, sino desde el cuerpo, rehuyendo cualquier explicación orgánica, biológica o mecánica de aquello que somos. Su apuesta, pues, va a contracorriente, puesto que tampoco pretende generar teoría del cuerpo y de la educación desde la evidencia científica (ese nuevo dogma de fe que ha colonizado la academia en todos los campos del conocimiento), sino desde la "experiencia encarnada" que, en su caso, se traduce en una práctica de pensamiento orientada por sus propias vivencias y percepciones, es decir, por aquello que siente. La autenticidad en torno a lo que piensa y produce la encuentra, pues, en ese sentir. Una autenticidad que acaba siendo verificada por las experiencias pedagógicas que explora a lo largo del libro, halladas en los márgenes donde se desarrollan hoy las resistencias educativas a cualquier forma de estigmatización u opresión corporal.

Pero, ¿qué son las pedagogías sensibles? De entrada, podemos decir que son aquellas pedagogías que intentan superar las lógicas clasificatorias que ha impuesto el paradigma "psi" en educación, un paradigma que nos habla de patrones de desarrollo, parámetros de "normalidad evolutiva" y, sobre todo, de trastornos, de un amplio mercado de trastornos que acaba siendo atendido también por un amplio mercado de respuestas psicoeducativas, médicas y, últimamente, neuroeducativas a fin de atender el malestar que planea hoy en el mundo de la educación. Unas respuestas que se dedican a interpretar, diagnosticar, clasificar y medicar los cuerpos para no dejarlos hablar. Nadie escucha, entonces, qué desean los sujetos que sostienen esos cuerpos. Y es que una cosa es diagnosticar o clasificar los cuerpos, y otra muy distinta cartografiarlos, tal y como hacía Fernand Deligny cuando dibujaba los mapas del deambular repetitivo de los niños autistas con los que convivió. Planella apuesta por esa cartografía, homenajeando así al gran educador francés, uno de sus grandes referentes a la hora de "soñar pedagogías sensibles", o lo que es lo mismo, una pedagogía de potencialidades que se encarna en hechos educativos moleculares, situados en los márgenes. Sin duda, este libro es también un mapa. Un mapa para todos aquellos que no se conforman con las estrecheces de una pedagogía normativa. Un mapa desde el que aprender de nuevo a mirar, con Gloria Anzaldúa, Valeria Flores, Urko Gato y tant*s otr*s que nos enseñan a descentrar nuestras epistemologías, cruzando fronteras, desplazando "las marcas de la educación en la piel" y abriendo, así, el camino hacia otras pedagogías conectadas con nuestros cuerpos y nuestros afectos.

Jordi Solé Blanch

Universitat Oberta de Catalunya jsolebla@uoc.edu 